\title{
Improving Syntax, Non-English Speakers Perspective
}

\author{
Almestareehi Kefah Mohamad
}

Jordan

\begin{abstract}
Syntax is a set of rules that govern the structure of sentences in the semantic arrangement to denote the lexical meaning but the question is whether these lexical elements can be used syntactically or not. Sentences can be made by using any syntactic pattern and they denote whether the sentences are simple, complex or compound. There have been many innovative ways to put these syntactic ways into the right use. But the truth in understanding the syntactic methods especially through the application of grammar could pose a serious problem to a non-English speaking learner who is willing to learn the English language. In this article, I have tried to explain simple ways for a non-English speaker to understand the importance of syntax in a generalised way. Sentences that require more thinking to express specific ideas can be more complex in their syntactic way. Every individual who is willing to learn English language may not be from literature or linguistic background and hence the need arises to simplify the syntactic approach in non-English speakers' perspective.
\end{abstract}

Keywords: Syntax, Syntactic Structures, acceptability, grammaticality, morphemes, grammar.

Abbreviations: Syntactic Structures (SS), Mother Tongue Influence (MTI)

\section{INTRODUCTION}

There is a systematic representation of syntactical order of sentences in every language. It is also quite evident that all the syntactic properties have not been deeply explored yet. But it is strongly believed that it takes years to master a language through proper systematic learning procedure and hence instead of trying to master the language in the same ways I believe there is a need to improvise. The syntactic and morphological structure mechanisms in building the structure of sentences is not the same in all the languages. This is particularly true when it comes to non-English speakers who are trying to master the English language. In order to overcome this criterion, the principle-based approach should be in a different perspective and hence every individual learner should learn to improvise the art of making sentences that are constructive and functional based rather than those that are purely governed by grammar rules. The syntax of English language should be categorised and postulated in a standard functional syntactic manner rather than endowed with genetic grammar specifics. As Poet and writer Wang Ping Says "She walks to a table, she walk to table... Language, like woman, Look best when free, undressed." ${ }^{[1]}$ She intrigues that as long as the meaning is conveyed the syntax really does not play a vital role.

Most of the non-English speakers try to learn the English language in the same old fashion by understanding the general rules of English grammar along with those of phonology and applied linguistics. Every individual is led in the same way and hence they end up using vernacular English with a lot of Mother Tongue Influence (MTI) that is clearly visible in the language used. This could be the beginning of the death of creativity that eventually consumes the imagination of the learner to improvise. In most of the academic and educational training centres, an individual learner who is basically of non-English-speaking background is initiated to follow the ways of the trainer (who may also have MTI). Instead of helping them to understand the language in their own way in order to improvise it in a better way, the non English speakers are forced to adopt what they are taught. This is really one of the major reasons why most of the non-English-speaking pupils are willing to consider the English language as a part of the syllabus and as a subject that they need to pass in order to complete their education. Instead of digging deeper into grammar or trying to understand it by translating into their native language, it is recommended that the imaginative thinking be more enhanced (without MTI) rather than the factual thinking which is filled with annoying grammar rules. As Dorothy L. Sayers who is a writer said, "Those who prefer their English sloppy have only themselves to thank if the advertisement writer uses his mastery of the vocabulary and syntax to mislead their weak minds." [2] 


\section{BACKGROUND}

The historical understanding of syntax can be dated back to thousands of years and Syntactic Structures (SS) have been applied in various forms. As Noam Chomsky said, "From now on I will consider a language to be a set (finite or infinite) of sentences, each finite in length and constructed out of a finite set of elements. All natural languages in their spoken or written form are languages in this sense." ${ }^{[3]}$ The nature of SS, judging syntactic structures through grammatical functions and the generalisations about construction of sentences seem to be quite annoying for a non-English speaker who is planning to learn the English language. To most of the English language learners, English language is a set of grammatical rules that are to be mastered in order to speak correct English. Though grammar plays a vital role in the initial stages of learning the English language, yet most of the learners are trying to understand the words in their grammatical sense rather than their application in usage. It is difficult for a non-English speaker to determine the form and content of the grammar. If the words of a sentence or not in a syntactic order there is a high possibility of misjudging the sentence because it is ungrammatical but on the other hand the intention of the speaker is conveyed anyhow. This is understood and manageable well when the speaker is trying to convey his needs rather than delivering a message. The importance of syntactic theorising about the distinction between acceptability and grammaticality has not played a vital role in the modern learning methods. In the words of Bent Jacobsen, "'the native speaker makes grammaticality judgments'. Nothing could be more mistaken." ${ }^{[4]}$ The easiest way to overcome this complication is to recognise the way individual morphemes and words constitute more difficult forms of sentences rather than trying to blindly apply those using grammatical or SS. Most of the Non English Speaking countries which value and consider English as an important international language are allocating huge money and resources to encourage individuals to learn English language through proper means in order to help their citizens achieve various tasks in the lives. In most of the non English speaking countries, English is the official language though there were negative implications in the initial stages of its introduction. Many new teaching methods and curriculum had to be brought in to stabilise the understanding of the peoples' point of view towards learning the English language. Most of the non-English speakers, especially the youngsters are desperate to learn the language in order to acquire technical and scientific language skills for pursuing their higher education and to have a better career. This is not the case of only the academicians but there are several other people who are striving to learn the English language to take their business to the next level or to even find a better job in English-speaking countries.

\section{DiSCUSSION}

When it is considered from a different perspective i.e. if a sentence that needs to be conveyed in a syntactical passive form is mistakenly conveyed in active voice, the scope of misunderstanding is rather high in both syntactic as well as grammatical sense. For example if the sentence "I was asked doubts in class" were to be conveyed as "I asked doubts in class" can generate huge misunderstanding. Hence a non-English speaker who is learning English language should not only be aware of transforming a sentence from active voice to passive voice but also they should be aware of the results of using a passive syntax in English language. The above-mentioned example is to show how an auxiliary verb can make the difference and above all if the speaker is not aware whether the verb "asked" (used in the above example) is in the past simple form or past participle form, both the speaker and the listener would definitely end up in a big confusion. Even an electronic device such as computer would not be able to differentiate the meaning of both the sentences since the error is never highlighted in such syntax. Transformation of sentences from active to passive and vice versa can be very painful for initial learners and hence the learners must be capable enough to improvise for conveying their sentences in the right way though their grammar may be weak. If the speaker is not sure of how to frame sentences in a syntactic passive structure, the speaker is advised to reframe the above-mentioned example i.e. "I was asked doubts in class" into "they asked me doubts in class". By doing so the speaker may not be strengthening the subject but the whole idea is definitely generated in a rightful manner which creates a comfortable environment for both the speaker as well as the listener. According to the statistics, most of the non-English speakers who work in different public and private sectors lack the ability to convey what they intend to say effectively and precisely in English language. It is quite unfortunate that most of them have at least nine years of primary education to learn the English language. Many research oriented programmes have been introduced in various nonEnglish speaking countries to improve the quality of teaching and learning the English language. Though these are true, the bitter truth is that unless a non-English speaker who wants to learn English 
adapts and improvises with the new ways that he or she is willing to apply, only then positive results can be witnessed. In comparison with other languages like Chinese, English language is much easier to learn as it is based on alphabets and also though syntactic rules are very strict in English language yet they are simple. As long as the basic syntactic procedures are properly applied to form sentences in English language, learning English can never be a difficult task.

\section{Conclusion}

It could be concluded that every individual who is a non-English speaker willing to learn English needs to be free to think and improvise in different ways. Syntax in English language is like blood to the body but it also doesn't mean that blood is the only thing that keeps the body alive. Likewise instead of just following the basic syntactic procedures of English-language, it is also advised to improvise according to the situation and use the mind to be innovative while learning the language rather than purely applying the grammatical rules and structures. Non English speakers who are learning English language should be cable of understanding the Syntax not only in a grammatical way but also in a way that could help them to arrange the words in the right sense to generate a meaningful meaning of the sentence spoken by them.

\section{REFERENCES}

[1] http://www.goodreads.com/author/show/110260.Wang_Ping

[2] Dorothy L. Sayers quotes (British Writer, 1893-1957)

[3] Noam Chomsky (1928), Syntactic Structures, p. 13, Mouton (1971)

[4] Bent Jacobsen (1992) Remarks on Acceptability and Grammaticality, p.7 [Online]. Available: (http://download2.hermes.asb.dk/archive/download/H08_01.pdf), [September 26, 2013].

[5] Chomsky, N. (1965): Aspects of the Theory of Syntax. Cambridge, Mass.: MIT Press

[6] Smith, N.V. (1989): The Twitter Machine. Reflections on Language. Oxford: Basil Blackwell

\section{AUTHORS' BIOGRAPHY}

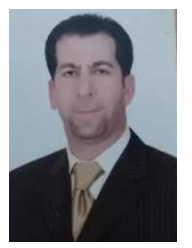

Almestareehi kefah Mohammad, was awarded the Ph.D degree in English (Applied Linguistics) from the Department of English, Mumbai University in 2003. Thereafter, he worked as an assistant professor in the departments of English of several universities in Jordan and Saudi Arabia. Presently, he is an assistant professor in the Department of English, Jazan University, Saudi Arabia.

$\mathrm{He}$ is interested in various branches of theoretical as well as applied linguistics specifically the effects of different linguistic variations between the native and second languages on the learning process of a second language. 